\title{
Long-term survival of the cemented Müller CDH stem: a minimum follow-up of 10 years
}

\author{
Yves Salentiny $^{1} \cdot$ Lukas Zwicky $^{1} \cdot$ Peter E. Ochsner ${ }^{1} \cdot$ Martin Clauss $^{1}$
}

Received: 22 November 2017 / Published online: 25 July 2018

(c) The Author(s) 2018

\begin{abstract}
Introduction Total hip arthroplasty in patients with altered anatomy of the hip and femur, such as in congenital dysplasia of the hip, is challenging and often requires specially designed stems. Müller straight stems have shown excellent long-term results; however, long-term data on the analogous cemented Müller CDH stem are still missing. The aim of this study was to analyze long-term survival, identify potential risk factors for aseptic loosening, and analyze radiological outcome of the cemented Müller CDH stems.

Materials and methods Between 01/1985 and 06/2005, 95 Müller CDH stems (Zimmer, Winterthur, Switzerland) made up of 3 different materials were cemented using 2 different bone cements: 38 of stainless steel/high-viscosity cement, 31 of a cobalt-chrome-based alloy (CoCr)/low-viscosity cement, and 26 of a titanium-based alloy (Ti)/low-viscosity cement. All patients had a prospective clinical and radiological follow-up according to the standards of our institution. The cumulative incidence for revision of the stem was calculated using a competing risk model. To identify demographic and implant-related risk factors for aseptic loosening of the stem, a multivariate regression model for competing risks was performed.

Results The cumulative risk of revision at 15 years was $12.5 \%$ (95\% CI 6.6-20.5\%) for aseptic loosening of the stem as endpoint, with marked differences for the various stem materials used: stainless steel $2.7 \%(0.2-12.3 \%)$, CoCr $12.9 \%(4.0-$ 27.3\%), and $\mathrm{Ti} 24.5 \%$ (9.6-43.1\%). Regression modeling revealed that Ti stems in combination with low-viscosity cement (HR 10.2) and implantation with an axis deviation greater than $3^{\circ}$ (HR 3.8) are risk factors for aseptic loosening.

Conclusions Long-term survival of the cemented Müller CDH stem is comparable to other Müller-type straight stems and uncemented implants. Similar to the original Ti Müller straight stem, the Ti Müller CDH stem also showed an increased risk for aseptic loosening and should, therefore, no longer be used.
\end{abstract}

Keywords Aseptic loosening $\cdot \mathrm{CDH} \cdot$ Cemented stem $\cdot$ Hip dysplasia $\cdot$ Risk factors $\cdot$ Total hip arthroplasty

\section{Introduction}

Treating osteoarthritis of the hip in patients with an altered anatomy is technically more challenging when using standard implants. Such an altered anatomy is observed in patients with congenital dyplasia of the hip (CDH), in patients with a severe varus position of the femoral neck, an increased antetorsion or a narrow medullary canal. Two-dimensional $[1,2]$ and three-dimensional analyses in an Asian [3, 4] and Caucasian [5] CDH population further demonstrated a straight femur with a distalized anterior femoral bow, making it even

Martin Clauss

martin.clauss@ksbl.ch

1 Clinic for Orthopedics and Trauma Surgery, Kantonsspital Baselland, Rheinstrasse 26, 4410 Liestal, Switzerland more difficult to fit a standard implant in the femoral canal in these particular cases.

Both Charnley and Harris developed special cemented $\mathrm{CDH}$ stems to address the difficulties faced in this specific patient group. Recently, long-term results were published showing a 20-year survival rate with aseptic loosening as the endpoint in $63 \%$ of the Charnley and in $78 \%$ of the Harris $\mathrm{CDH}$ stem [6]. Excellent results have been reported for the small variant of the Exeter stem for patient with small femurs [7]. Good long-term survival rates in $\mathrm{CDH}$ patients have also been reported for uncemented [8] and modular stem designs [9] with survival rates of $96 \%$ after 12 years and $97 \%$ after 8-year follow-up, respectively.

In hip arthroplasty, the original Müller straight stem is one of the most common implanted cemented straight stems with excellent long-term results [10-13]. The cemented 
Müller CDH stem belongs to the same implant series. Appropriate indications for its usage amongst others are hip joints with small and hypoplastic bony anatomy with narrow femoral canals as well as osteoarthritis secondary to congenital or childhood disorders of the hip. However, up to now, no data are available showing its long-term outcome.

The aim of this study was to analyze long-term survival, identify potential risk factors for aseptic loosening, and analyze radiological outcome of the cemented Müller CDH stems.

\section{Materials and methods}

\section{Demographics}

Between 01/1985 and 06/2005, a consecutive series of 95 total hip arthroplasties (THA) using a Müller CDH straight stem (Zimmer, Winterthur, Switzerland), were performed in 86 patients with bony abnormalities. All patients were followed prospectively with a standardized follow-up protocol. All surgeries were carried out personally or under direct supervision of one of the authors (PEOXXX).

75 of the 86 patients were female. The median age at the time of surgery was 65 years (range $43-88$ years). Indications for THA were primary osteoarthrosis (OA) in 50 cases, $\mathrm{CDH}$ in 24 cases, fracture and avascular necrosis in 6 cases respectively, rheumatoid OA in 5 cases, and OA secondary to Legg-Calvé-Perthes disease in 4 cases. All patients were operated in supine position through a lateral transgluteal approach. Indications to use the Müller CDH straight stem, instead of a regular stem, were (1) a narrow medullary canal and/or (2) a deteriorated proximal femoral geometry, e.g., lacking of a femoral calcar and/or (3) cases of dysplasia and malpositioned greater trochanter additionally needing a trochanteric osteotomy [14]. During the whole-study period, operative technique (except the type of bone cement) and patient aftercare remained unchanged.

\section{Implants}

The Müller CDH straight stem is a double-tapered design and was manufactured as a monobloc stem with a $22-\mathrm{mm}$ head and a CCD angle of $130^{\circ}$ (Fig. 1). It was available in five different sizes. Although the manufacturer did not change the design of the stem over the years, it was manufactured in three different biomaterials, which were implanted in our institution: 31 CoNiCrMo (CoCr) stems (1985-1997), $26 \mathrm{Ti}-6 \mathrm{Al}-7 \mathrm{Nb}$ (Ti) stems (1988-1993), and 38 stainless steel stems (1997-2005, Table 1).

All stems were cemented using the second-generation cementing techniques with an autologous distal bone plug. Two different types of antibiotic-free cement were used:

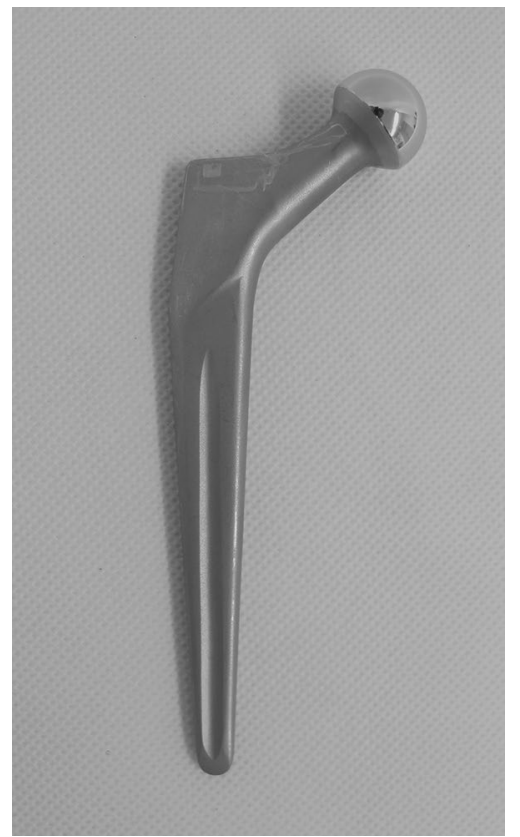

Fig. 1 Müller CDH stem (Zimmer, Winterthur, Switzerland). The stem is smooth blasted. The anterior and posterior sides present a longitudinal groove

Table 1 Characteristics of the different implanted Müller CDH straight stems

\begin{tabular}{llll}
\hline$N$ & 31 & 26 & 38 \\
$\begin{array}{l}\text { Material } \\
\begin{array}{c}\text { Surface rough- } \\
\text { ness }\left(\mathrm{R}_{\mathrm{a}}\right)\end{array}\end{array}$ & $\mathrm{CoNiCr}$ & $\mathrm{Ti6Al7Nb}$ & Stainless steel \\
\begin{tabular}{l} 
Cement \\
\hline
\end{tabular} & Sulfix-60 & Sulfix-60 & Palacos R \\
\hline
\end{tabular}

low-viscosity cement (Sulfix-60, Zimmer) between 1985 and 1997 (57 hips, CoCr and Ti stems), and high-viscosity cement (Palacos R, Heraeus, Wehrheim, Germany) between 1998 and 2005 (38 hips, stainless steel stems). In 17 hips, a trochanteric osteotomy was performed to allow proper medullary canal entry. The stem was combined with two different cup systems, namely an acetabular reinforcement ring (ARR, Zimmer) with a cemented polyethylene cup (67 hips) or an uncemented pressfit cup (SL-II, Zimmer, 28 hips).

\section{Follow-up and radiological analysis}

Patients were followed prospectively according to the standardized protocol at our institution [13]. The follow-ups were scheduled at 4 months, 1, 2, and 5 years, and every 5 years thereafter.

Standardized anterior-posterior radiographs centered on the symphysis, showing that the entire prostheses were performed at follow-ups. The radiological assessment was 
based on the most recent radiograph available from the follow-ups or in case of a revision of the stem, the last available radiograph prior to revision surgery [13, 15] (Fig. 2).

Osteolysis at the bone-cement interface was defined as any progressive and newly developed endosteal bone loss with a diameter $>3 \mathrm{~mm}[13,16]$. A radiolucent line at the prosthesis-cement interface, not visible on the first postoperative radiograph, was considered debonding of the stem-cement interface [13]. The alignment of the stem was evaluated on the radiograph 4 months postoperatively by comparing the femoral bone axis to the stem axis. The axis of the femoral bone was determined by drawing a line through the center of two lines, drawn at two different heights of the femur, at the level of the prosthesis, perpendicular to the cortex. An analogous axis was drawn through the stem of the prosthesis. A varus or valgus alignment of less than $3^{\circ}$ was considered to be neutral [17]. Subsidence was defined as being an increase of radiolucency between the shoulder of the prosthesis and proximal cement in Gruen zone 1 [12]. Cortical atrophy of the femur was defined as being a longitudinal thinning of the femoral cortex due to intracortical porosis, without any measurable changes of the diameter of the femur [18]. Debonding, osteolysis, and cortical atrophy of the femur were evaluated in the Gruen zones [19]. Stems were considered radiographically loose when osteolysis in all Gruen zones was present and/or subsidence was $>10 \mathrm{~mm}[15,20]$.

Ambiguous findings were discussed with the senior investigator $(* *$ blinded $* *)$ and agreed upon.

\section{Statistics}

A survival analysis with death as a competing risk was performed to determine the cumulative revision rate (CRR) of: (1) aseptic loosening of the stem and (2) stem loosening for any reason. Patients without any revision were censored at the date of last contact. The analysis was halted once the number of patients at risk was smaller than 25 .

In addition, time to aseptic loosening of the stem was analyzed using a multivariate proportional hazards model for the subdistribution of death as a competing risk [21]. Factors included in the full model were known risk factors for aseptic loosening of the original Müller straight stem such as age $(<60,60-70,>70$ years $)$, sex, stem material ( $\mathrm{CoCr}, \mathrm{Ti}$, and stainless steel), cup fixation (cemented and uncemented), stem size (5.0, 7.5, 10.0, and $\geq 12.5)$ [15], type of cement (Sulfix, Palacos) [15], and stem alignment (neutral, $>\left|3^{\circ}\right|$ ). Selection of the parameter in the final model was performed using the Bayesian information criteria (BIC) $[22,23]$.

Categorical data were compared using Fisher's exact test or Pearson's Chi-square test, while, for continuous variables, a $t$ test was used. The level for statistical significance was set at $p<0.05$.

Statistical analyses were performed using R statistical package version 3.1.3 [24].
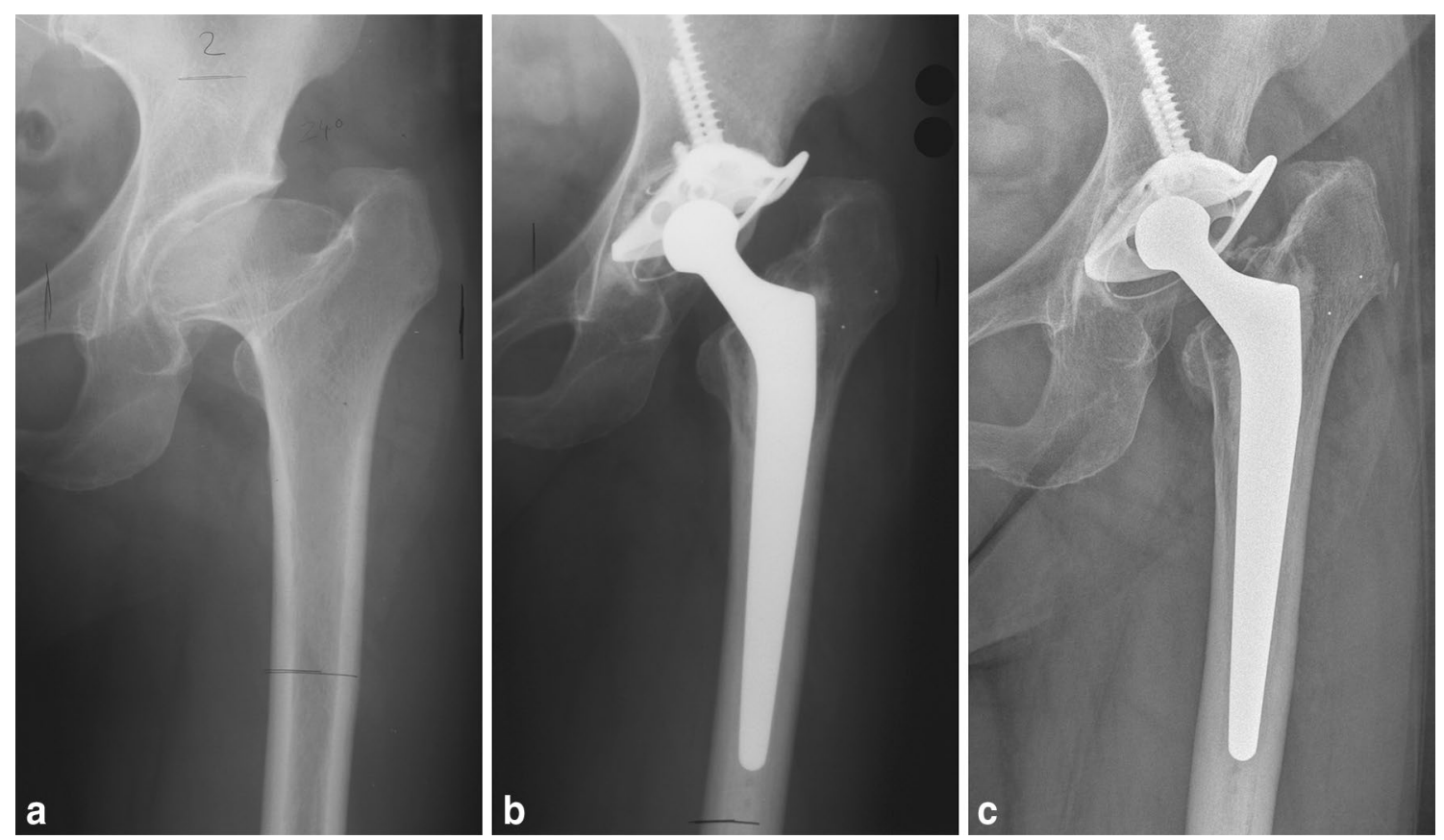

Fig. 2 a 55-year-old female patient with a Perthes hip, b reconstruction with an acetabular reinforcement ring and CDH stem, $\mathbf{c}$ at 18-year follow-up, with no signs of any radiological changes 


\section{Results}

\section{Follow-up}

Twenty-two patients [34 hips, $15 \mathrm{CoCr}(48 \%), 14 \mathrm{Ti}(54 \%)$, and 5 stainless steel (13\%)] had died of causes unrelated to the THA 11 (0.7-23) years after implantation; one patient (stainless steel group) was lost to follow-up after 6 years. The median clinical follow-up was $12(0.7-30)$ years.

\section{Cumulative revision rate}

17 stems were revised: 13 for aseptic loosening, 2 due to infection, 1 after recurrent dislocations, and 1 after a periprosthetic femoral fracture. There was one additional isolated cup revision.

The cumulative revision rate (CRR) for aseptic loosening at 15 years was $12.5 \%$ (95\% CI 6.6-20.5\%); the CRR for stem loosening for any reason at 15 years was $16.4 \%$ (9.6-24.7\%). In contrast, the competing risk for death at 15 years was $32.1 \%$ (22.0-42.7\%). CRR for aseptic loosening of the stem of the various materials were $2.7 \%$ $(0.2-12.3 \%), 12.9 \%(4.0-27.3 \%)$, and $24.5 \%$ (9.6-43.1\%) for stainless steel, $\mathrm{CoCr}$, and Ti, respectively ( $p=0.10$, Fig. 4$)$.

\section{Risk factors for aseptic loosening of the stem}

The hazard ratios (HR) of the full model are presented in Table 2. Based on these estimates, a model was built using the BIC difference to the null model using a "forward" approach. As Palacos was only used in combination with implants made of stainless steel, the factor cement was merged with the factor material. The final model included stem material/type of cement $[\mathrm{CoCr} / \mathrm{Sulfix}$, HR 4.42 (0.54-36.0), $p=0.16$; Ti/Sulfix, HR 10.2 (1.16-89.1), $p=0.04]$ and stem alignment [HR 3.84 (1.23-12.0), $p=0.02]$.

\section{Radiological results}

For a total of 13 hips, no radiographs were available, leaving 82 hips for radiological analysis. The median radiological follow-up was $10(0.2-30)$ years.

Osteolysis was found in 20 of the 82 stems. It appeared primarily on the proximal medial stem side in the Gruen zones $6(n=14)$ and $7(n=13)$. In 12 of 13 stems revised due to aseptic loosening, osteolysis was present. Sex $(p=0.45)$ and age $(p=0.70)$ had no influence on the occurrence of osteolysis. No stem was rated radiologically loose without being revised.

Debonding was seen in 20 of 82 stems, mainly on the proximal lateral side of the stem in Gruen zone 1.11 of the 13 stems revised for aseptic loosening showed debonding, while only 9 of the remaining 69 stems not revised for aseptic loosening showed debonding $(p<0.001)$.

A total of 68 stems had neutral alignment. 13 stems were implanted with a varus alignment $\left(3.1-5.2^{\circ}\right)$, and 1 stem had a valgus alignment of $3.5^{\circ}$.
Table 2 Hazard ratios (HRs) for aseptic loosening of the $\mathrm{CDH}$ Müller straight stem

\begin{tabular}{|c|c|c|c|c|c|c|}
\hline Parameter & No failure & $\begin{array}{l}\text { Aseptic } \\
\text { loosen- } \\
\text { ing }\end{array}$ & Full model HR $(95 \% \mathrm{CI})$ & $p$ & Final model HR (95\%CI) & $p$ \\
\hline \multicolumn{7}{|l|}{ Age } \\
\hline$<60$ & 28 & 5 & Ref & & & \\
\hline $60-70$ & 29 & 6 & $0.70(0.18-2.73)$ & 0.60 & & \\
\hline$>70$ & 25 & 2 & $0.48(0.07-3.36)$ & 0.46 & & \\
\hline \multicolumn{7}{|l|}{ Sex } \\
\hline Male & 8 & 3 & Ref & & & \\
\hline Female & 74 & 10 & $0.29(0.03-2.84)$ & 0.29 & & \\
\hline \multicolumn{7}{|l|}{ Cup fixation } \\
\hline ARR & 58 & 9 & Ref & & & \\
\hline SL-II & 24 & 4 & $3.52(0.57-21.6)$ & 0.17 & & \\
\hline \multicolumn{7}{|c|}{ Stem material/cement } \\
\hline Steel/palacos & 37 & 1 & Ref & & Ref & \\
\hline Ti/sulfix & 20 & 6 & $17.5(3.11-97.8)$ & 0.001 & $10.2(1.16-89.1)$ & 0.04 \\
\hline CoCr/sulfix & 25 & 6 & $5.15(0.64-41.5)$ & 0.16 & $4.42(0.5-36.0)$ & 0.16 \\
\hline \multicolumn{7}{|l|}{ Alignment } \\
\hline Neutral & 60 & 8 & Ref & & Ref & \\
\hline$>13^{\circ}$ & 9 & 5 & $4.13(0.85-20.13)$ & 0.08 & $3.84(1.23-12.0)$ & 0.02 \\
\hline
\end{tabular}


16 of 82 stems showed subsidence with a median of 3 (1-15) $\mathrm{mm}$. 6 of the 13 stems revised for aseptic loosening had subsided of which 5 subsided more than $2 \mathrm{~mm}(6,7,10$, 13 , and $15 \mathrm{~mm}$ ).

Cortical atrophy was seen in 35 of 82 cases, mainly in Gruen zones $2(n=29)$ and $6(n=32)$. Cortical atrophy was seen in 2 of the cases in which the stems were revised for aseptic loosening compared to 33 in the group which were not revised for aseptic loosening $(p=0.06)$. Hips showing cortical atrophy had a statistically significant longer radiological follow-up time [12.7 (6.1) vs. 8.3 (5.5) years, $p=0.001]$.

A trochanteric osteotomy was performed in 17 hips with evident pseudarthrosis in seven cases (Table 3).

\section{Discussion}

The Müller CDH stem shows good long-term survival rates with a cumulative revision rate (CRR) of 12.5\% (6.6-20.5\%) at 15 years with aseptic loosening as the endpoint (Fig. 3). This is superior to other cemented dysplasia stems [6] and comparable to uncemented dysplasia stems $[6,8,9,14$, 25-27]. Comparable results have also been published with the small versions of the polished cemented Exeter stem [7].

$\mathrm{CRR}$ with aseptic loosening as the endpoint was lower for stems made of stainless steel (2.7\%) compared to Ti (24.5\%) (Fig. 4). The performance of the stainless steel Mueller CDH stem in combination with low-viscosity cement was superior to other cemented stems and similar to uncemented stems $[8,9]$. This can be attributed to the higher modulus of elasticity of stainless steel causing less cement damage [28, 29]. Clauss et al. [30] concluded, in their publication, that cemented straight stems should be made of a material with high flexural strength (e.g., steel or $\mathrm{CoCr}$ ), which seems to be true also for the Müller CDH stem. Analyzing the stems with a high flexural strength, the HR for aseptic loosening of CoCr/sulfix stems was $4.42(p=0.16)$ compared to steel/ palacos stems. The use of a different type of cement may

Table 3 Radiological results

\begin{tabular}{lccc}
\hline & CoCr & Ti & Stainless steel \\
\hline No radiological follow-up & 3 & 6 & 3 \\
Osteolysis & 6 & 7 & 7 \\
Debonding & 7 & 7 & 6 \\
Cortical atrophy & 13 & 8 & 14 \\
Alignment & & & \\
$\quad$ Neutral & 21 & 17 & 30 \\
$\quad$ Varus & 6 & 3 & 4 \\
$\quad$ Valgus & 1 & 0 & 0 \\
Subsidence & 4 & 4 & 8 \\
\hline
\end{tabular}

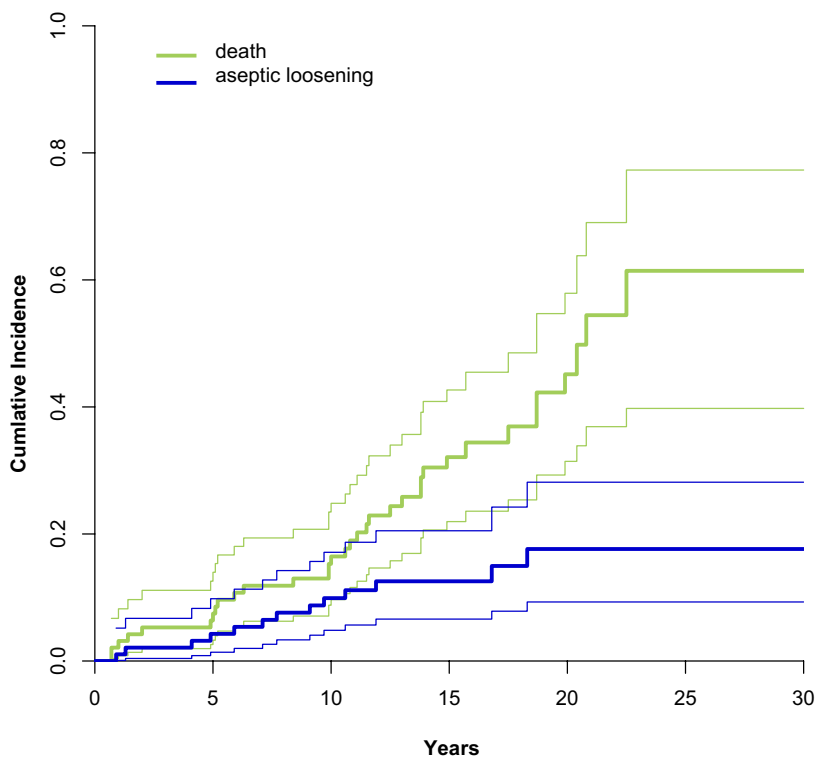

Fig. 3 Cumulative incidence (with 95\% confidence intervals) for aseptic loosening of the stem and death

explain why the CoCr stems showed a tendency toward higher CRR in comparison to stainless steel stems, even though they have approximately equal stiffness. A recently published prospective randomized trial including 711 Muller type straight stems made of CoCr found a statistically nonsignificant difference in favour for high-viscosity Palacos over low-viscosity sulfix [15].

The Müller CDH stem was developed for hips with altered anatomy showing small femora, or dysplastic hips

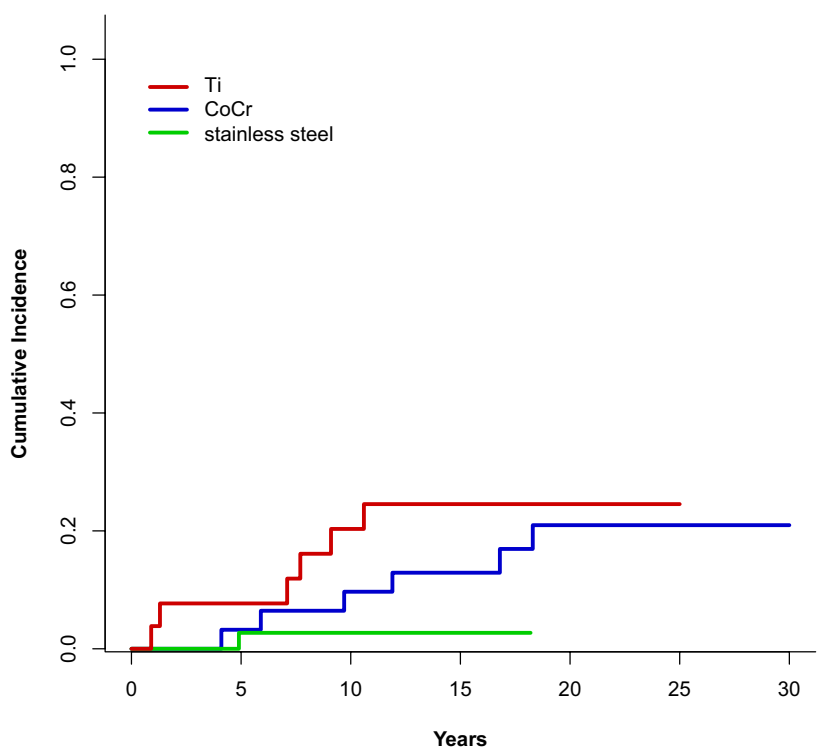

Fig. 4 Cumulative risk for revision due to aseptic loosening of the stem: 38 stainless steel (green), $31 \mathrm{CoCr}$ (blue), and $26 \mathrm{Ti}$ (red) 
presenting an increased CCD angle with a small head, allowing for a wedge-type stem with additional cement fixation. It follows the same cementing philosophy as the original Müller straight stem, however, with extended possible indications [18, 31]. For cemented Müller straight stems, Clauss et al. [13] have shown osteolysis to occur mainly in the Gruen zones 6 and 7 with debonding first appearing superolaterally, which is in accordance to the radiological findings of the Müller CDH straight stem. Both stems have a similar double-tapered design with a groove running down the lower two-thirds of the stem allowing for analogous fixation in the femoral shaft. In our series, osteolysis was found in $92 \%$ of stems revised for aseptic loosening. Only two of the stems revised showed cortical atrophy. Patients showing cortical atrophy had a longer follow-up period, substantiating the findings of Poss et al. [32] and being in accordance with the original Müller straight stem [13]. Cortical atrophy, therefore, seems to be a rather positive sign.

This study has a few limitations, namely that two different cement types were used and that different cup designs were combined with the Müller CDH stem. It is well known from the Norwegian Arthroplasty register that low-viscosity bone cement is a risk factor for increased aseptic loosening [33, 34]. The authors even concluded that the effect of the cement on aseptic loosening itself might be higher than the prosthesis brand [35]. However, we are not able to prove statistically whether cement or stem material is the more important risk factor for aseptic loosening for stems with a comparable flexural stiffness (CoCr/sulfix vs SS/palacos). As, to the latter, a superior cup may protect an inferior stem which also applies the other way around linking aseptic loosening of the cup to the stem $[30,36]$. In our series, $2 / 3$ of the Müller CDH stems were combined with an ARR. This cup has shown to have excellent long-term results in a series of 123 consecutive total hip arthroplasties between 1981 and 1986 [37] as well as in a high number of complex cases between 1984 and 2003 [38]. Another limitation was the use of different stem materials at different time intervals. Although the surgical technique concerning surgical experience and patient care over time remained the same during the whole-study period, the possibility of general improvement in patient care over time cannot completely be excluded.

To our knowledge, the present study is the first one reporting long-term survival and radiological outcome of the cemented Müller CDH stem after a mean of 15 years. The outcome of the stainless steel Mueller CDH stem with low-viscosity cement is similar to other stems with similar indications.

In conclusion, the $\mathrm{CDH}$ Müller straight stem shows good-to-excellent long-term survival and substantiates the findings of other $\mathrm{CDH}$ implants and Müller straight stems. Similar to the results of the original Müller straight stem, these data suggest that the material of the stem should be of high modulus of elasticity (e.g., stainless steel or cobalt chrome). Cemented CDH Müller straight stems made of Ti should no longer be used and the use of high-viscosity cement is recommended. Therefore, the ongoing use of the Müller CDH stem in contemporary THA for patients which meet the indication criteria would be justified, especially when using modern third-generation cementing techniques.

\section{Compliance with ethical standards}

Conflict of interest On behalf of all authors, the corresponding author states that there is no conflict of interest.

Ethical approval The study was approved by the local ethics committee. All procedures performed in studies involving human participants were in accordance with the ethical standards of the institutional and/ or national research committee and with the 1964 Helsinki declaration and its later amendments or comparable ethical standards. For this type of study, formal consent is not required.

Open Access This article is distributed under the terms of the Creative Commons Attribution 4.0 International License (http://creativeco mmons.org/licenses/by/4.0/), which permits unrestricted use, distribution, and reproduction in any medium, provided you give appropriate credit to the original author(s) and the source, provide a link to the Creative Commons license, and indicate if changes were made.

\section{References}

1. Argenson JN, Flecher X, Parratte S, Aubaniac JM (2007) Anatomy of the dysplastic hip and consequences for total hip arthroplasty. Clin Orthop Relat Res 465:40-45. https://doi.org/10.1097/ BLO.0b013e3181576052

2. Papachristou G, Hatzigrigoris P, Panousis K, Plessas S, Sourlas J, Levidiotis C, Chronopoulos E (2006) Total hip arthroplasty for developmental hip dysplasia. Int Orthop 30(1):21-25. https://doi. org/10.1007/s00264-005-0027-1

3. Noble PC, Kamaric E, Sugano N, Matsubara M, Harada Y, Ohzono K, Paravic V (2003) Three-dimensional shape of the dysplastic femur: implications for THR. Clin Orthop Relat Res 417:27-40 (Doi: 30.3097/01.blo.0000096819.67494.32)

4. Sugano N, Noble PC, Kamaric E, Salama JK, Ochi T, Tullos HS (1998) The morphology of the femur in developmental dysplasia of the hip. J Bone Joint Surg Br 80(4):711-719

5. Argenson JN, Ryembault E, Flecher X, Brassart N, Parratte S, Aubaniac JM (2005) Three-dimensional anatomy of the hip in osteoarthritis after developmental dysplasia. J Bone Joint Surg Br 87(9):1192-1196. https://doi. org/10.1302/0301-620X.87B9.15928

6. Digas G, Georgiades G, Lampropoulou-Adamidou K, Hartofilakidis G (2013) The twenty-year survivorship of two CDH stems with different design features. Eur J Orthop Surg Traumatol 23(8):901-906. https://doi.org/10.1007/s00590-012-1105-x

7. Chiu KH, Cheung KW, Chung KY, Shen WY (2011) Exeter small femoral stem for patients with small femurs. J Orthop Surg (Hong Kong) 19(3):279-283. https://doi.org/10.1177/230949901101900 303 
8. Schuh A, Schraml A, Hohenberger G (2009) Long-term results of the Wagner cone prosthesis. Int Orthop 33(1):53-58. https://doi. org/10.1007/s00264-007-0460-4

9. Benazzo FM, Piovani L, Combi A, Perticarini L (2015) MODULUS stem for developmental hip dysplasia: long-term followup. J Arthroplast 30(10):1747-1751. https://doi.org/10.1016/j. arth.2015.04.021

10. Erivan R, Villatte G, Khelif YR, Pereira B, Galvin M, Descamps S, Boisgard S (2017) The Muller self-locking cemented total hip prosthesis with polyethylene liner: after twenty years, what did they become? Int Orthop 41(1):47-54. https://doi.org/10.1007/ s00264-016-3191-6

11. Nikolaou VS, Korres D, Lallos S, Mavrogenis A, Lazarettos I, Sourlas I, Efstathopoulos N (2013) Cemented Muller straight stem total hip replacement: 18 year survival, clinical and radiological outcomes. World J Orthop 4(4):303-308. https://doi.org/10.5312/ wjo.v4.i4.303

12. Raber DA, Czaja S, Morscher EW (2001) Fifteen-year results of the Muller CoCrNiMo straight stem. Arch Orthop Trauma Surg 121(1-2):38-42

13. Clauss M, Luem M, Ochsner PE, Ilchmann T (2009) Fixation and loosening of the cemented Muller straight stem: a long-term clinical and radiological review. J Bone Joint Surg Br 91(9):11581163. https://doi.org/10.1302/0301-620X.91B9.22023

14. Berry DJ, Muller ME (1993) Chevron osteotomy and single wire reattachment of the greater trochanter in primary and revision total hip arthroplasty. Clin Orthop Relat Res 294:155-161

15. Clauss M, Bolliger L, Brandenberger D, Ochsner PE, Ilchmann $\mathrm{T}$ (2016) Similar effect of stem geometry on radiological changes with 2 types of cemented straight stem: the Muller stem and the Virtec stem compared in 711 hips. Acta Orthop 87(2):120-125. https://doi.org/10.3109/17453674.2015.1104153

16. Joshi RP, Eftekhar NS, McMahon DJ, Nercessian OA (1998) Osteolysis after Charnley primary low-friction arthroplasty. A comparison of two matched paired groups. J Bone Joint Surg Br 80(4):585-590

17. Iwase T, Wingstrand I, Persson BM, Kesteris U, Hasegawa Y, Wingstrand H (2002) The ScanHip total hip arthroplasty: radiographic assessment of 72 hips after 10 years. Acta Orthop Scand 73(1):54-59. https://doi.org/10.1080/000164702317281413

18. Clauss M, Ilchmann T, Zimmermann P, Ochsner PE (2010) The histology around the cemented Muller straight stem: a post-mortem analysis of eight well-fixed stems with a mean follow-up of 12.1 years. J Bone Joint Surg Br 92(11):1515-1521. https://doi. org/10.1302/0301-620X.92B11.25342

19. Gruen TA, McNeice GM, Amstutz HC (1979) "Modes of failure" of cemented stem-type femoral components: a radiographic analysis of loosening. Clin Orthop Relat Res 141:17-27

20. Harris WH, McCarthy JC Jr, O'Neill DA (1982) Femoral component loosening using contemporary techniques of femoral cement fixation. J Bone Joint Surg Am 64(7):1063-1067

21. Fine JP, Gray RJ (1999) A proportional hazards model for the subdistribution of a competing risk. J Am Stat Assoc 94(446):496509. https://doi.org/10.2307/2670170

22. Scrucca L, Santucci A, Aversa F (2010) Regression modeling of competing risk using R: an in depth guide for clinicians. Bone Marrow Transplant 45(9):1388-1395. https://doi.org/10.1038/ bmt.2009.359

23. Schwarz G (1978) Estimating the dimension of a model. Ann Stat $6(2): 461-464$
24. R Core Team (2015) R: A language and environment for statistical computing. R Foundation for Statistical Computing 2015, Vienna, Austria. http://www.R-project.org/

25. Claramunt RT, Marques F, Leon A, Vila G, Mestre C, Verdie LP (2011) Total hip replacement with an uncemented Wagner cone stem for patients with congenital hip dysplasia. Int Orthop 35(12):1767-1770. https://doi.org/10.1007/s00264-011-1218-6

26. Kang JS, Moon KH, Kim RS, Park SR, Lee JS, Shin SH (2011) Total hip arthroplasty using S-ROM prosthesis for dysplastic hip. Yonsei Med J 52(4):655-660. https://doi.org/10.3349/ ymj.2011.52.4.655

27. Wagner H, Wagner M (2000) Cone prosthesis for the hip joint. Arch Orthop Trauma Surg 120(1-2):88-95

28. Janssen D, Aquarius R, Stolk J, Verdonschot N (2005) Finiteelement analysis of failure of the Capital Hip designs. J Bone Joint Surg Br 87(11):1561-1567. https://doi.org/10.1302/0301620X.87B11.16358

29. Maurer TB, Ochsner PE, Schwarzer G, Schumacher M (2001) Increased loosening of cemented straight stem prostheses made from titanium alloys. An analysis and comparison with prostheses made of cobalt-chromium-nickel alloy. Int Orthop 25(2):77-80

30. Clauss M, Gersbach S, Butscher A, Ilchmann T (2013) Risk factors for aseptic loosening of Muller-type straight stems: a registry-based analysis of 828 consecutive cases with a minimum follow-up of 16 years. Acta Orthop 84(4):353-359. https://doi. org/10.3109/17453674.2013.810517

31. Langlais F, Kerboull M, Sedel L, Ling RS (2003) The 'French paradox.'. J Bone Joint Surg Br 85(1):17-20

32. Poss R, Staehlin P, Larson M (1987) Femoral expansion in total hip arthroplasty. J Arthroplast 2(4):259-264

33. Havelin LI, Espehaug B, Vollset SE, Engesaeter LB (1995) The effect of the type of cement on early revision of Charnley total hip prostheses. A review of eight thousand five hundred and seventynine primary arthroplasties from the Norwegian Arthroplasty Register. J Bone Joint Surg Am 77(10):1543-1550

34. Furnes O, Lie SA, Havelin LI, Vollset SE, Engesaeter LB (1997) Exeter and charnley arthroplasties with Boneloc or high viscosity cement. Comparison of 1,127 arthroplasties followed for 5 years in the Norwegian Arthroplasty Register. Acta Orthop Scand 68(6):515-520

35. Furnes O, Havelin LI, Espehaug B (2005) Properties of bone cement: which cement should we choose for primary THA? In: Breusch S, Malchau H (eds) The well cemented total hip arthoplasty. Theory and practice. Springer, Berlin, pp 103-106

36. Clement ND, Biant LC, Breusch SJ (2012) Total hip arthroplasty: to cement or not to cement the acetabular socket? A critical review of the literature. Arch Orthop Trauma Surg 132(3):411-427. https ://doi.org/10.1007/s00402-011-1422-2

37. Gill TJ, Sledge JB, Muller ME (1998) Total hip arthroplasty with use of an acetabular reinforcement ring in patients who have congenital dysplasia of the hip. Results at five to fifteen years. J Bone Joint Surg Am 80(7):969-979

38. Sirka A, Clauss M, Tarasevicius S, Wingstrand H, Stucinskas J, Robertsson O, Ochsner PE, Ilchmann T (2016) Excellent long-term results of the Muller acetabular reinforcement ring in primary total hip arthroplasty: a prospective study on radiology and survival of 321 hips with a mean follow-up of 11 years. Acta Orthop 87(2):100-105. https://doi.org/10.3109/17453 674.2015.1103607 